\title{
Formula Feeding and Associated Factors among Mothers with Infants 0-6 Months Old in Mettu Town, South West Ethiopia
}

Abeza Mitiku ( $\sim$ abzmtk@gmail.com )

\section{Research}

Keywords: Formula feeding, Infant aged 0-6 months, Mettu town

Posted Date: October 12th, 2021

DOl: https://doi.org/10.21203/rs.3.rs-965060/v1

License: (c) (i) This work is licensed under a Creative Commons Attribution 4.0 International License.

Read Full License 


\section{Abstract \\ Background}

Adequate nutrition during infancy is essential for the normal development and future wellbeing of the child. Despite the fact that breast milk is optimal nutrition for infants during the first six months of life, the duration of breastfeeding has been declining and being replaced by formula feeding particularly in urban communities of developing countries including Ethiopia. However, relatively little information is available regarding formula feeding in Ethiopia; particularly in Mettu town.

\section{Methods}

Community-based cross-sectional study was conducted in Mettu town from May, 17 to July 1, 2021, among 366 mothers with infants 0-6 months old. A simple random sampling technique was employed. Pre-tested semi-structured questionnaires were used to collect data. Descriptive statics and multivariable logistic regression were performed, and variables with a $p$-value $<0.05$ in the final model were declared statistically significant with formula feeding.

\section{Result}

The prevalence of formula feeding among the study participants was $28.4 \%, 95 \%$ [Cl: 24.0-33.0]. In multivariable logistic regression analysis primparity [AOR=3.3, 95\% $\mathrm{Cl}:(1.71-6.26)]$, cesarean delivery [AOR=2.6, 95\% Cl:(1.28-5.35)], initiation of breastfeeding after 24hrs [AOR=3.7,95\% Cl:(1.24-10.05)] employed mothers [AOR=2.4, 95\% Cl:(1.29-4.49] poor knowledge [AOR=2.6, 95\% Cl:(1.49-4.73)] and positive attitude toward formula feeding $[A O R=2.4,95 \% \mathrm{Cl}$ : $(1.27-4.84)]$ were significantly associated with formula feeding.

\section{Conclusion}

About one-third of mothers were formula feeding their infant. Primi parity, initiation of breast milk after $24 \mathrm{hrs}$, cesarean delivery, and poor maternal knowledge and positive attitude were significantly associated with formula feeding. Hence, education on infant feeding for pregnant and lactating mothers, and supporting primipara mothers and as well as mothers who deliver by cesarean section should be implemented at health facility and community level.

\section{Introduction}

Infancy is a critical period in which rapid physical growth, cognitive and emotional development takes place. Adequate nutrition during infancy is essential for normal development and also fundamental for lifelong health and wellbeing (1). Breast milk is universally recommended to be the best and complete 
food for infants. Thus, early initiation of breastfeeding within one hour of birth, exclusive breastfeeding of infants for the first 6 months of life and continued breastfeeding with appropriate complementary foods for two or more years is a basis for growth and development $(2,3)$.

Despite the fact that breastfeeding is strongly advocated, there is a shifting of exclusive breastfeeding practice towards the introduction of formula feeding particularly in industrialized countries and urban communities of developing countries including Ethiopia (4-6).

Because of the effects of globalization, urbanization, changes in the nature of women's work, increased availability of formula milk in supermarkets, and promotion of breast milk substitutes through advertising in various media, the proportion and duration of breastfeeding is declining and being replaced by formula feeding (7).

Infants on formula feeding are more vulnerable to acute respiratory infections (ARI), otitis media, allergies, gastroenteritis, diarrhea, pneumonia and sudden infant death syndrome. And also they are at higher risk of developing non-communicable disease such as diabetes mellitus, decreased cognitive development and increase risk of obesity future in their life $(3,8)$.

World Health Organization (WHO) developed the International Code of Marketing of BMS (Breast Milk Substitute) in 1981 to promote and support the EBF (Exclusive Breastfeeding). In addition, WHO 2016 assembly has made a national implementation of the code to guide ending the inappropriate promotion of foods for infants and young children. However, According to WHO 2020 report, only 136 (70\%) of 194 WHO Member States (countries) had enacted legal measures with provisions to implement the code (9).

Since 2016, the Ethiopian government has implemented various guidelines to support breastfeeding and guide the promotion of BMS, including the "Infant Formula and Follow-up Formula Directive No. 30/2016" and the "Food Advertisement Directive 33/2016".(10,11) However, according to studies conducted in DireDawa, Jimma and Adds Ababa, Ethiopia $21.4 \%, 61.9 \%$, and $46.2 \%$ of mothers were practicing formula feeding respectively $(6,12,13)$.

Maternal occupation, educational status, maternal health status, delivery by cesarean section (C/S), attitude toward formula milk, advertisement, and economic factors give impact to the mothers to feed their infants with infant formula $(6,14,15)$.

Parents may not know about the nutritional contents of formula milk, and the health impact of feeding their infants with formula milk. There are a few studies conducted regarding formula feeding in Ethiopia, particularly in Mettu town. Hence, this study aimed to assess factors influencing formula feeding among mothers with infants 0 up to 6 months old in Mettu town.

\section{Materials And Methods}

\subsection{Study setting and period}


The study was conducted in Mettu town and data was collected from May 17 to July 1, 2021. Mettu town is located $600 \mathrm{~km}$ away from of Addis Ababa, the capital city of the country. The town has divided into three kebeles with an estimated total population of 49,538 and 10,321 households. The estimated number of women of the reproductive age group was 9,214 . The town has one public hospital, one health center; three health posts with twelve HEW, eleven medium private clinics, six private small clinics, twelve drug vendors and three pharmacies.

\subsection{Study Design and Population}

A community based cross sectional study design was employed in Mettu town from May 17 to July 1 , 2021. All mothers with index infants of less than 6 months old and living in Mettu tow were the source population, whereas mothers with index infants less than 6 months old and full filling the inclusion criteria were study population and included in the study. Mothers who have a medical reason for the use of infant formula and those who cannot complete the interview because of severe medical / psychiatric problems were excluded in the study.

\subsection{Sample Size Determination and Sampling Procedure}

The required sample size was determined using single population proportion formula by taking the proportion of formula feeding as $61.9 \%$ (13), confidence of $95 \%$, margin of error of $5 \%$,the initial sample size was 362 . By considering $5 \%$ non-response rate, the final sample size was 380 .

Before data collection, a list of mothers who gave live birth within six months interval was collected from delivery books of both public and private health institutions in the town. Accordingly, we found total of 659 mothers who gave live births within six months interval in Mettu town. A sampling frame was prepared and the required numbers of mothers who will be selected from each kebele were determined based on proportion to population size allocation. Finally, study participants were selected using a computer-generated simple random sampling technique.

\subsection{Data Collection Tool and Technique}

Data was collected by face-to-face interview using a semi-structured and pre-tested questionnaire. The questionnaires were derived from related articles $(4,6,12-14)$. The questionnaire had five parts (socioeconomic and demographic characteristics, maternal health service and child characteristics, maternal knowledge of formula feeding, maternal attitude toward formula feeding, formula feeding and related characteristics)

The questionnaires was first prepared in English and translated into Afan Oromo (local language) then translated back to English by expert who had a good ability of two languages to check the consistency. Prior to data collection, the questionnaires were pre-tested on $5 \%(20)$ sample size in other town, which is not part of the actual data collection. Based on pre-test some modifications were done to the questionnaires. The internal consistency of independent variable with five-point Likert scale was checked by Cronbach's alpha. 
Data was collected by six urban Health Extension Workers using pre-tested and semi-structured questionnaires through house-to-house visit of mothers with an index of infants less than six months old. Two BSc nurse were recruited as a supervisor during data collection. If the eligible mother was absent from the home at the time of data collection, a revisit was done three times, and the mother who was absent at the third visit was considered as non-respondent.

Two days training was given for data collectors and supervisors by the principal investigator on data collection tools, data collection techniques, approach to the interviews and maintaining the privacy and confidentiality of the respondents. Every day after data collection, questionnaires were reviewed and checked for completeness by the supervisors and principal investigator

\subsection{Operational definition}

\section{Formula feeding}

Feeding an infant less than 6 months old with formula milk using a bottle, rubber nipple, or cup as either supplement to breast milk or a complete breast milk substitute. It was measured by a "Yes" (1) and "No" (2) question. The mothers who answered "Yes" to the question were considered as a mother who fed their child with formula milk (13).

\section{Antenatal service utilization}

Having at least one visit of health facility for checkup purpose of obstetric condition during the pregnancy of the current index child (16).

\section{Attitude toward formula feeding}

Respondents were asked a set of questions contains 7 items that ranges from strongly disagree to strongly agree using five-point Likert scale. When the total score of each respondent is close to 35 , it shows the most favorable attitude and when the score is close to 7 , it shows the most unfavorable attitude towards formula feeding. Based on the total summation of the scales, respondents were classified as having a negative attitude toward formula feeding if they scored less than 21 , neutral if they scored 21 and positive attitude score above 21(17).

\section{Knowledge of formula feeding}

was measured using yes/no dichotomous that consisted of 6 items. The answer to each question was analyzed as know and do not know. From the six items, each correct answer was coded as " 1 " which is (known) and each wrong answer " 0 " (don't know). The maximum attainable score was six and the minimum possible score is zero. Respondent whose their knowledge scores equal to mean and above were categorized as having good knowledge whereas those score below the mean score were categorized as having poor knowledge of formula feeding(18).

\section{Wealth index}


22 items were used to assess the household assets. Factor scores were derived using Principal Components Analysis (PCA) and then the composite scores were ranked into three tertiles. The first $30 \%$ tertiles were classified as poor whereas the last $30 \%$ tertiles were classified as rich)(19).

\subsection{Data Processing and Analysis}

All data were checked visually, coded, and entered into Epi-data version 4.6, then exported into SPSS version 26 software packages for analysis. After categorizing and defining variables, descriptive analysis was carried out for each of the independent variables using frequencies, cross tabulation and percentages.

Before performing PCA for variables explaining household wealth index, all the necessary assumptions and prerequisites were checked. The degree of association between independent and dependent variables was assessed using AOR (Adjusted Odds Ratio with 95\% confidence interval. Simple binary logistic regression analysis was performed to select candidate variables for multivariable analysis. A variable with $P$-value $<0.25$ was taken as candidate for the multiple regression analysis and $p$-value $<0.05$ was declared as statistically significant in the final model.

Pseudo regression was performed to check multi-collinearity between independent variables, the minimum tolerance and maximum variance inflation (VIF) factor was found to be 0.60 and 1.69 respectively. For the finally fitted multivariable logistic regression model, the adequacy of the model to predict the outcome variables was checked by Hosmer-Lemeshow goodness-of-fit and the $P$-value $>0.05$.

\section{Results}

\subsection{Socio-Economic and demographic characteristics of participants}

Total of 366 mothers with an infant aged 0-6 months were participated in the study, making a response rate of $96.3 \%$. The mean age of the respondents was 25.5 years $(S D \pm 4.4)$ which was in the range of 25 to 34 years, with a minimum age of 18 and maximum age of 39. Almost all $359(98.1 \%)$ of mothers were married, by religion 136 (37.2\%) were protestant, 286 (78.1\%) were Oromo in ethnicity. Regarding educational status and occupation, 24 (6.6\%) had no formal education while 144 (39.3\%) were college and above, $171(46.7 \%)$ were housewives. In terms of wealth status, one-third of them were $122(33.4 \%)$ ranked poor (table 1).

Table 1 Table 2 Socio-demographic characteristics of the mothers with infants-age 0-6 months old, Mettu town, Southwest Ethiopia, 2021 


\begin{tabular}{|c|c|c|c|}
\hline variables $(\mathrm{N}=366)$ & Category & Frequency & Percent \\
\hline \multirow{3}{*}{ Age of mother } & $15-24$ & 176 & 48.1 \\
\hline & $24-34$ & 176 & 48.1 \\
\hline & $\geq 35$ & 14 & 3.8 \\
\hline \multirow[t]{2}{*}{ Marital status } & Married & 359 & 98.1 \\
\hline & Single/divorced & 7 & 1.9 \\
\hline \multirow{3}{*}{ Religion } & Orthodox & 133 & 36.3 \\
\hline & Protestant & 136 & 37.2 \\
\hline & Muslim & 97 & 26.5 \\
\hline \multirow[t]{4}{*}{ Maternal education } & No formal education & 24 & 6.6 \\
\hline & Primary education & 87 & 23.8 \\
\hline & Secondary education & 111 & 30.3 \\
\hline & College and above & 144 & 39.3 \\
\hline \multirow[t]{3}{*}{ Ethnicity } & Oromo & 286 & 78.1 \\
\hline & Amara & 43 & 11.7 \\
\hline & Other ${ }^{\mathbf{a}}$ & 37 & 10.1 \\
\hline \multirow[t]{5}{*}{ Maternal occupation } & Housewife & 171 & 46.7 \\
\hline & Merchant & 65 & 17.8 \\
\hline & Government employee & 87 & 23.7 \\
\hline & Private employee & 12 & 3.3 \\
\hline & Other $\mathbf{b}$ & 31 & 8.5 \\
\hline \multirow[t]{3}{*}{ Wealth index } & Poor & 122 & 33.4 \\
\hline & Medium & 124 & 33.8 \\
\hline & Rich & 120 & 32.8 \\
\hline
\end{tabular}

a: Tigre, Gurage and Kaffa , b: Student, un-employed and daily labor

\subsection{Maternal health service Utilization and infant related characteristics}

Regarding the obstetric experience of the participants, 211 (57.4\%) of them were multi-para. Almost all 364 (99.5) were attended ANC service. However, only 58 (15.8\%) of them had four and above ANC visits. Regarding infant feeding counseling during ANC, 221 (60.4\%) of them were counseled on infant feeding. The majority of the study participants, 339 (92.6) gave birth at public health institutions, and 294 (80.3\%) were delivered spontaneously/vaginal. The majority of them, $323(88.3 \%)$ were received postnatal care within $24 \mathrm{hrs}$ of their delivery.

All of the infants were breastfed at any time and $280(76.5 \%)$ of mothers were initiated breast within 1 hour of delivery. The mean age of the infants was 3.2 months $(S D \pm 1.4)$ with a minimum of 1 month and a maximum of 6 months (table 2). 
Table 2 Maternal health service utilization and infant characteristics among mothers with infant 0-6 months old Mettu town, Southwest Ethiopia, 2021

\begin{tabular}{|c|c|c|c|}
\hline Variable $(N=366)$ & Category & Frequency & Percent \\
\hline \multirow[t]{2}{*}{ Parity } & Prim-Para & 156 & 42.6 \\
\hline & Multi-Para & 210 & 57.4 \\
\hline \multirow{2}{*}{ ANC follow up } & Yes & 364 & 99.5 \\
\hline & No & 2 & 0.5 \\
\hline \multirow[t]{2}{*}{ Number of visits } & $<4$ visit & 308 & 84.2 \\
\hline & $\geq 4$ visit & 58 & 15.8 \\
\hline \multirow[t]{2}{*}{ Counseling on infant feeding } & Yes & 221 & 60.4 \\
\hline & No & 145 & 39.6 \\
\hline \multirow[t]{2}{*}{ Place of delivery } & Public health institution & 339 & 92.6 \\
\hline & Private health institution & 27 & 7.4 \\
\hline \multirow[t]{2}{*}{ Mode of delivery } & Normal/Vaginal & 294 & 80.3 \\
\hline & $\mathrm{C} / \mathrm{S}$ & 72 & 19.7 \\
\hline \multirow[t]{2}{*}{ PNC care } & Yes & 323 & 88.3 \\
\hline & No & 43 & 11.7 \\
\hline \multirow[t]{3}{*}{ Age of the infant } & $<2$ months & 113 & 30.9 \\
\hline & $2-3$ months & 134 & 36.6 \\
\hline & 4-6 months & 119 & 32.5 \\
\hline \multirow[t]{2}{*}{ Sex of infant } & Male & 178 & 48.6 \\
\hline & Female & 188 & 51.4 \\
\hline \multirow[t]{2}{*}{ Ever breastfed } & Yes & 366 & 100 \\
\hline & No & 0 & 0 \\
\hline \multirow[t]{3}{*}{ Timing of breast milk initiation } & Within $1 \mathrm{hr}$. & 280 & 76.5 \\
\hline & 1-23hrs & 59 & 16.1 \\
\hline & After 24 hrs. & 27 & 7.4 \\
\hline
\end{tabular}

ANC: Antenatal Care, PNC: Postnatal care, C/S: Cesarean section

\subsection{Maternal knowledge of formula feeding}


Regarding knowledge of respondents on infant formula, 298 (81.4\%) of them were heard about infant formula and the most common source of information was peer/neighbors 209 (70.1\%) followed by TV/radio 127 (42.6\%). Among these, 129 (43.3\%) of the respondents were replied infant formula increases a baby's immunity, $181(60.1 \%)$ replied infant formula contributes to a baby's brain development. $41(13.8 \%)$ of the respondents replied infant formula is more nutritious than breast milk, and $205(68.8 \%)$ respondents do not know the future health impact of formula feeding. The mean score was 2.9 with $\mathrm{SD} \pm 1.35$. Based on the mean knowledge score, the participants were categorized as having poor knowledge 135 (46.1\%) while 158 (53.9\%) good knowledge (table 3).

Table 3 maternal knowledge of formula feeding among mothers with infant 0-6-months old Mettu town, Southwest Ethiopia, 2021

\begin{tabular}{|c|c|c|c|}
\hline \multirow{2}{*}{$\begin{array}{c}\text { Question } \\
\text { Have you ever heard about infant formula }\end{array}$} & Response & Frequency & Percent \\
\hline & $\begin{array}{l}\text { Yes } \\
\text { No }\end{array}$ & $\begin{array}{l}298 \\
69\end{array}$ & $\begin{array}{l}81.4 \\
18.9\end{array}$ \\
\hline Source information & $\begin{array}{l}\text { peer/neighbors } \\
\text { TV/Radio } \\
\text { family } \\
\text { Health } \\
\text { professional }\end{array}$ & $\begin{array}{l}209 \\
127 \\
55 \\
50\end{array}$ & $\begin{array}{l}70.1 \\
42.6 \\
18.5 \\
16.8\end{array}$ \\
\hline $\begin{array}{l}\text { Does infant formula increase your baby's } \\
\text { immunity? }\end{array}$ & $\begin{array}{l}\text { Yes } \\
\text { No }\end{array}$ & $\begin{array}{l}129 \\
169\end{array}$ & $\begin{array}{l}43.3 \\
56.7\end{array}$ \\
\hline $\begin{array}{l}\text { Does formula feeding contribute to child brain } \\
\text { development }\end{array}$ & $\begin{array}{l}\text { Yes } \\
\text { No }\end{array}$ & $\begin{array}{l}181 \\
117\end{array}$ & $\begin{array}{l}60.7 \\
39.3\end{array}$ \\
\hline $\begin{array}{l}\text { Does formula feeding increase the risk of } \\
\text { diarrhea and other infection }\end{array}$ & $\begin{array}{l}\text { Yes } \\
\text { No }\end{array}$ & $\begin{array}{l}107 \\
191\end{array}$ & $\begin{array}{l}35.9 \\
64.1\end{array}$ \\
\hline $\begin{array}{l}\text { Does formula feeding increase the risk of } \\
\text { childhood obesity }\end{array}$ & $\begin{array}{l}\text { Yes } \\
\text { No }\end{array}$ & $\begin{array}{l}131 \\
167\end{array}$ & $\begin{array}{l}44 \\
56\end{array}$ \\
\hline $\begin{array}{l}\text { Does infant formula is more nutritious than breast } \\
\text { milk }\end{array}$ & $\begin{array}{l}\text { Yes } \\
\text { No }\end{array}$ & $\begin{array}{l}41 \\
257\end{array}$ & $\begin{array}{l}13.8 \\
86.2\end{array}$ \\
\hline $\begin{array}{l}\text { Does formula feeding affect future health status of } \\
\text { the baby }\end{array}$ & $\begin{array}{l}\text { Yes } \\
\text { No }\end{array}$ & $\begin{array}{l}93 \\
205\end{array}$ & $\begin{array}{l}31.2 \\
68.8\end{array}$ \\
\hline
\end{tabular}

\subsection{Maternal attitude toward formula feeding}


Regarding the attitude of respondents toward infant formula, 107 (35.9\%) disagreed on formula feeding ensures optimal health for the baby, while $143(48 \%)$ were agreed. $238(79.9 \%)$ of them were disagree that formula feeding is more convenient than breast milk while, $19(6.4 \%)$ agreed. One-third of the respondents 95 (31.9\%) disagreed on the idea that infant formula is advised when baby's growth is sluggish/weak while $131(44 \%)$ were agreed. 198 (66.4\%) of the participants disagree on the idea that your baby is willing to feed formula milk than breast milk while $26(8.7 \%)$ agreed. $186(62.4 \%)$ of them disagree with the idea that formula feeding gives you more comfort than breastfeeding while $39(13.1 \%)$ agreed.

Based on the summation of the scales, $188(63.1 \%)$ of participants were categorized as having a negative attitude while $37(12.4 \%)$ and $73(24.5 \%)$ were categorized as having neutral and positive attitudes respectively (table 4 ).

Table 4 Maternal attitude toward formula feeding among mothers with infant 0-6 months of old Mettu town, Southwest Ethiopia, 2021

\section{Variables}

Formula feeding ensures optimal health for the baby

It is more convenient than breast milk

It is advised when baby's growth is sluggish/weak

Your baby is willing to feed formula milk than breast milk

It gives you more comfort than breast feeding

It makes your baby smart

Rich family feed their baby with formula milk 132(44.3\%) $110(36.9 \%) \quad 56(18.8)$ while poor provides only breast milk

\begin{tabular}{lcc} 
& \multicolumn{2}{c}{ Responses } \\
\hline Disagree & Neutral & Agree \\
107(35.9\%) & $48(16.1 \%)$ & $143(48 \%)$ \\
& & \\
$238(79.9 \%)$ & $41(13.8 \%)$ & $19(6.4)$
\end{tabular}

95(31.9\%) 72(24.2) 131(44\%)

$198(66.4 \%) \quad 74(24.8 \%) \quad 26(8.7 \%)$ 186(62.4\%) $73(24.5 \%) \quad 39(13.1 \%)$ 107(35.9\%) $144(48.3 \%) \quad 47(15.8 \%)$

\subsection{Formula feeding and related characteristics}

Among total study participants, 104 (28.4\%) [95\% Cl 24.0-33.0] were formula-fed their babies. Among respondents practicing formula feeding, $99(95.2 \%)$ of them were feeding combination (both breast milk and formula) while only 5 (4.8\%) were feeding their babies with only formula milk. The main reason for the initiation of infant formula was breast milk insufficiency 44 (42.3\%), busy for work 36 (34.6\%) and 
sluggish growth of baby 24(23.1). The average age of initiating infant formula was 2.3 months $S \mathrm{~d} \pm 1.04$ which is found within 2-3 age interval.

\subsection{Factors associated with formula feeding}

On multivariable logistic regression analysis, prim-para mothers (AOR=3.2 $95 \mathrm{Cl}$ : 1.71-6.27), delivery by caesarian section (AOR=2.62 95\% Cl: 1.28-5.35), initiation of breast milk after $24 \mathrm{hrs}$. (AOR=3.5.95 Cl: 1.27-10.05), employed mothers ( $\mathrm{AOR}=2.4,95 \% \mathrm{Cl}: 1.29-4.09)$, poor knowledge of formula feeding ( $\mathrm{AOR}=$ $2.695 \% \mathrm{Cl}: 1.49-4.81)$ and positive attitude toward formula feeding (AOR=2.4 $95 \mathrm{Cl}$ : 1.49-4.73) were significantly associated with formula feeding (table 5).

Table 5 Multivariable analysis of factors associated with formula feeding among mothers with infant 0-6-month-old Mettu town, Southwest Ethiopia, 2021 


\begin{tabular}{|c|c|c|c|c|c|}
\hline Variable & \multicolumn{2}{|c|}{ Formula feeding } & & & $\overline{P-}$ \\
\hline & Yes (\%) & No (\%) & ${ }_{(95 \% \mathrm{CI})}^{\mathrm{COR}}$ & $\begin{array}{l}\mathrm{AOR} \\
(95 \% \mathrm{CI})\end{array}$ & value \\
\hline $\begin{array}{c}\text { Age of mother } \\
15-24 \\
25-34 \\
35 \text { above }\end{array}$ & $\begin{array}{l}34(19.3) \\
64(36.4) \\
6(42.9)\end{array}$ & $\begin{array}{l}142(80.7) \\
112(63.6) \\
8(57.1)\end{array}$ & $\begin{array}{l}0.31(0.104- \\
0.98) \\
0.762(0.25- \\
2.29)\end{array}$ & $\begin{array}{l}0.4(0.09- \\
1.71) \\
1.2(0.28- \\
4.82)\end{array}$ & $\begin{array}{l}0.23 \\
0.8\end{array}$ \\
\hline
\end{tabular}

Maternal education

\begin{tabular}{llllll} 
No formal education & $2(8.3)$ & $22(91.7)$ & \multicolumn{2}{c}{1} & \\
Primary education & $22((25.3)$ & $65(74.7)$ & $3.7(0.80-$ & $3.5(0.65-$ & 0.14 \\
Secondary & $30(27)$ & $81(73)$ & $17.12)$ & $19.81)$ & 0.08 \\
College/above & $50(34.7)$ & $94(65.3)$ & $4.2 \quad(0.90-$ & $4.5(0.83-$ & 0.04 \\
& & & $18.38)$ & $24.81)$ & \\
& & & $5.8(1.32-$ & $2.3(0.39-$ & \\
& & & $25.90)$ & $13.58)$ &
\end{tabular}

Employment status

\begin{tabular}{clllll} 
un employed & $60(22.5)$ & $207(77.5)$ & \multicolumn{1}{c}{1} & \\
employed & $44(44.4)$ & $55(55.6)$ & $\begin{array}{l}2.7(1.69- \\
4.50)\end{array}$ & $\begin{array}{l}2.4(1.29- \\
4.19)^{* *}\end{array}$ & 0.005 \\
& & & $4.5)$ &
\end{tabular}

Wealth status

\begin{tabular}{llllll} 
poor & $22(18.9)$ & $99(81.1)$ & \multicolumn{1}{c}{1} & \\
medium & $38(30.6)$ & $86(69.4)$ & $1.9(1.05-$ & $1.18(0.55-$ & 0.06 \\
rich & $43(35.80$ & $77(64.2)$ & $3.44)$ & $2.52)$ & 0.07 \\
& & & $2.4(1.33-$ & $2(0.93-4.43)$ & \\
& & & $4.32)$ & &
\end{tabular}

Parity

$\begin{array}{llllll}\text { Primipara } & 55(35.3) & 101(64.7) & 1.8(1.02- & 3.27(1.71- & >0.001 \\ \text { multipara } & 49(23.3) & 161(76.7) & 2.83) & 6.27)^{* *} & \end{array}$

Frequency of ANC visit

$\begin{array}{llllll}<4 \text { visits } & 94(30.5) & 214(69.5) & 2.1(1.02- & 2(0.84-5.33) & 0.09 \\ \geq 4 \text { visits } & 10(17.2) & 48(82.8) & 4.34) & & \end{array}$

Mode of delivery

\begin{tabular}{llllll} 
Spontaneously & $62(21.1)$ & $232(78.9)$ & \multicolumn{1}{c}{1} & \\
C/s & $42((58.3)$ & $30(41.7)$ & $\begin{array}{l}5.2(3.03- \\
9.04)\end{array}$ & $\begin{array}{l}2.62(1.28- \\
5.35)^{* *}\end{array}$ & 0.008
\end{tabular}

Timing of breast milk initiation

Sex of infant

\begin{tabular}{clllll} 
Within 1 hour & $64(22.9)$ & $216(77.1)$ & \multicolumn{1}{c}{1} & \\
$1-23$ hour & $24(40.70$ & $35(59.3)$ & $2.3(1.28-$ & $1.5(0.74-$ & 0.24 \\
After 24 hrs. & $16(59.3)$ & $11(40.7)$ & $4.17)$ & $3.18)$ & 0.018 \\
& & & $4.9(2.16-$ & $3.5(1.74-$ & \\
& & & $11.11)$ & $10.0)^{* *}$ &
\end{tabular}

$\begin{array}{llllll}\text { male } & 61(34.3) & 117(65.7) & 1.6(1.05- & 1.5(0.87- & 0.2 \\ \text { female } & 43(22.9) & 145(77.1) & 2.82) & 2.82) & \\ & & & & 1 & \end{array}$


Age of infant

$>2$ months

22(19.5)

$91(80.5)$

$1.8(1.04-$

1.3(0.6-2.72)

0.46

2-3 months

42(31.3)

92(68.7)

3.41)

2(0.9-4.56)

0.051

4-6 months

40(33.6) 79(66.4)

$2.2(1.14-$

3.82)

Knowledge

Poor

$60(44.4)$

75(55.6)

2(1.27-3.37)

2.6(1.27-

$4.74)^{* *}$

0.001

Good

44(27.8) 114(72.2)

1

58(30.9)

13(35.1)

33(45.2)
$130(69.1)$
$24(64.9)$
$40(54.8)$

1
$1.4(0.57-$
$2.57)$
$1.8(1.06-$
$3.22)$
$1.7(0.74-$

4.07)

2.4(1.49-

$4.74) * *$

Note: $* *$ denote statistically significant variables in multivariable logistic regression at $p$ value <0.05, COR: Crude Odds Ratio, AOR: Adjusted Odds Ratio

\section{Discussion}

This study has attempted to assess the prevalence of formula feeding and associated factors among mothers with infants 0-6 months of age in Mettu town. Accordingly, the study found that $28.4 \%$ of mothers in the study area were formula feeding their babies. Primi-parity, delivery by $\mathrm{C} / \mathrm{S}$, timing of breast milk initiation, maternal employment status, maternal knowledge and attitude toward formula milk were significantly associated with formula feeding.

The prevalence of formula feeding in this study is comparable with a study conducted at Agaro town $29 \%$ (20), and Dire-Dawa $21.4 \%$ (12), whereas, it is higher compared to the study conducted at Holeta $13.5 \%$ (21) and Gonder $12.4 \%$.(22) The prevalence of formula feeding in this study is lower compared to the study conducted in Jimma (65\%) (13) and Adis Abeba 47\%.(6), China 88\% (23), Staten Island, New York $65 \%$ (24), Pakistan 38\% (25), East Malaysia 73.7\% (26), Egypt 47\% (4), and Nigeria 38.3\% (5) The inconsistency might be due to due to the difference in the operational definition of formula feeding among the current study, differences in socio-economic status among study participants, and study period.

Regarding predictors of formula feeding, primipara mothers were 3.2 times more likely to practice formula feeding than multipara mothers. This finding is consistent with studies conducted in Taiwan (27), Malaysia (28), and Egypt (29). The reason might be due to lack of knowledge on the benefits of breastfeeding and ignorance of the benefits of breastfeeding. In addition, postpartum primiparous mothers may face problems such as breast milk insufficiency, difficulty of motherhood, and worrying about their body image. The presence of this stress leads to insufficient breast milk secretion(30). 
In this study mode of delivery was significantly associated with formula feeding, compared to those mothers who gave their birth vaginally, mothers deliver by caesarian section were 2.6 times more likely to initiate formula feeding to their babies. The finding of this study is in line with studies conducted in DireDawa (12), Addis Abeba (6), Egypt (29),Western Nepal (31), Indonesia (32) and North Jordan (33). There might be delayed initiation of breast milk after $\mathrm{C} / \mathrm{S}$ delivery that led to early introduction of formula feeding, which further decreases lactogenesis. In addition, maternal stress-related fear of the surgical procedure may also another factor that reduce breast milk secretion by impairing oxytocin secretion (34).

Mothers who initiated breastfeeding after 24 hours of delivery were 3.5 times more likely to initiate formula feeding compared to those who initiated breastfeeding within 1 hour of delivery. This finding is in line with a study conducted in Addis Abeba (6). The possible reason might be, as the time interval between delivery and initiation of breastfeeding is increases, there is a probability for the initiation of prelacteal feeding which in turn leads to decreased lactogenesis and inadequate breast milk secretion.

Maternal employment status was significantly associated with formula feeding. Employed mothers were 2 times more likely to initiate formula than un-employed mothers. This finding is consistent with studies conducted in Indonesia (32), India (35), Namibia (36), North Jordan (33), and Gonder town (22). This could be due to employed mothers were more scheduled with their outside work and have no adequate time for their baby to breastfeed. In addition, the absence of private breastfeeding or pumping areas in their workplace could be a reason for formula feeding.

Contrary to this finding, study conducted in Sokoharjo, Centarl Java reported that working mothers had 2 times less chance of formula feeding their babies (37). The reason for this discrepancy might be due presence of a well stablished policy that support breast feeding at their work place and also maternal experience of pumping a breast milk and storing for their babies before going to their workplace.

In this study, maternal knowledge of formula milk was significantly associated with formula feeding. Mothers those had poor knowledge of formula milk were about three times more likely to practice formula feeding than those with good knowledge. In other word having a good knowledge of formula feeding reduce the probability of not formula feeding by $62 \%$. The finding is similar with a study in Jimma.(13) This might be mothers with poor knowledge of formula feeding would have a probability of inadequate breastfeeding knowledge that leads them to initiate formula milk to their babies. Mother those had inadequate knowledge of infant formula were more likely shaped by effect of infant formula promotion that derived them formula feeding their babies(14).

Maternal attitude toward formula feeding is one of the predictors of formula feeding. Mothers who had a positive attitude toward formula feeding were two times more likely to initiate formula milk to their babies, compared to those who had a negative and neutral attitude toward formula feeding. In other words, having a negative attitude toward formula feeding reduces the likelihood of formula feeding by $60 \%$. The finding is consistent with studies conducted in Jimma(13) and Sukoharjo, Central Java (37). This could be due to a women who had a positive attitude could be easily derived to initiate formula milk to their babies when they found well-packaged formula milk at pharmacies and supermarkets (26). 


\subsection{Limitation of the study}

This study has its own limitation. First, since data were collected by the verbal report of the participants, there might be a possibility of response bias. Second, the study did not assess the qualitative perspective of formula feeding.

\section{Conclusion}

The current study reported that about one-third of mothers were feeding their infants with formula milk. Mode of delivery, parity, the timing of breast milk initiation, maternal employment status, maternal knowledge and attitude of formula feeding were found to be significantly associated with formula feeding. Hence, education on infant feeding for all pregnant and lactating mothers, encouraging early initiation of breastfeeding after delivery, supporting primipara mothers and as well as mothers who deliver by cesarean section should be implemented at health facility and community level.

\section{Abbreviations}

AOR: Adjusted Odds Ratio; COR: Crude Odds Ratio; Cl: Confidence Interval, ANC: Antenatal Care, PNC: Postnatal Care

\section{Declarations}

\section{Data Availability}

The data set analyzed during the current study are available from the corresponding author on reasonable request.

\section{Acknowledgment}

We would like to acknowledge Jimma University, department of nutrition and dietetics, and Mettu town health office for their support throughout the study period. We also grateful to thank data collectors, supervisors and study participants for their valuable contribution.

\section{Authors' contributions}

AM, developed the proposal and data collection tool, collected the data, carried out the statistical analysis and drafted the manuscript. MT, RK and WA conceived the study, supervised the data collectors and reviewed the manuscript. All authors read and approved the final manuscript.

\section{Funding}

The authors did not get any funding for his study, and it was entirely supported by the authors. 


\section{Ethical Approval and Consent to Participate}

Ethical clearance was obtained from ethical review board of Jimma University, Institute of Health Science (Reference number: IHR 42/2021) and submitted to Mettu town health office. The letter of permission was obtained from Mettu town health office. Before beginning the data collection, written consent was obtained from the study participants, after clear information was provided about the objectives of the study. The study was conducted accordance with Helsinki declaration. Participants were informed that they had full right to discontinue or refuse to participate in the study, and information obtained from them would be kept confidential.

\section{Conflict of Interest}

The authors declare that they have no competing interests regarding the publication of this article.

\section{Author details}

${ }^{1}$ Department of Public Health, College of Health Science, Mettu University, P.O. Box 318, Mettu, Ethiopia

${ }^{2}$ Department of Health Service Management, Faculty of Public Health, Institute of Health, Jimma University, Jimma, Ethiopia,

${ }^{3}$ Department of Nutrition and Dietetics, Faculty of Public Health, Institute of Health, Jimma University, Jimma, , Ethiopia,

\section{References}

1. Benjam Cabellero.Paul M.Finglas and Fidel Toldra. ENCYCLOPEDIA OF FOOD AND HEALTH. 2016. 230-234 p.

2. WHO. To Survival and Beyond: [Internet]. swezerland; 2010 [cited 2021 Mar 8]. Available from: https://www.paho.org/hq/dmdocuments/2010/Technical brief. Early initiation of breastfeeding. The key to survival and beyond.pdf.

3. Victora CG, Bahl R, Barros AJD, França GVA, Horton S, Krasevec J, et al. Breastfeeding 1 Breastfeeding in the 21st century: epidemiology, mechanisms, and lifelong eff ect. 2016.

4. Tawfik S, Saied D, Mostafa O, Salem M, Habib E. Formula Feeding and Associated Factors among a Group of Egyptian Mothers. 2019;7(11):1854-9.

5. Leshi O, Sanusi RA. Breastfeeding Knowledge and Practice of Mothers with Infants Less than Six Months Old in Kosofe Local Government of Lagos State Breastfeeding Knowledge and Practice of Mothers with Infants less than Six Months Old, in Kosofe Local Government of Lagos Sta. Niger J Nutr Sci. 2014;35(October).

6. Taye AA, Asegidew W, Taderegew MM, Bizuwork YG, Zegeye B. Formula feeding practice and associated factors among mothers with infants 0-6 months of age in Addis Ababa, Ethiopia: a 
community-based cross-sectional study. Ital J Pediatr. 2021;47(1):1-9.

7. Baker P, Smith J, Mccoy D, Santos T, Neves PA, Piwoz E, et al. First-food systems transformations and the ultra-processing of infant and young child diets: The determinants, dynamics and consequences of the global rise in commercial milk formula consumption. Matern \$ child Nutr. 2020; (July):1-18.

8. Tomy.Gutierez. Food Science,Technology and Nutrition for Babies and Children. Springer Nature Switzerland AG; 2020. 1 p.

9. WHO. Marketing of breast-milk substitutes: national implementation of the international code, status report 2020 [Internet]. 2020 [cited 2021 Mar 12]. Available from: https://www.who.int/publicationsdetail-redirect/9789240006010.

10. Laillou A, Gerba H, Zelalem M, Moges D, Abera W, Chuko T, et al. Is the legal framework by itself enough for successful WHO code implementation? A case study from Ethiopia. Matern Child Nutr. 2021;17(1):1-13.

11. Ethiopian, Food. Medicine and Health Care Administration and Control Authority Infant Formula and Follow up Formula Directive. Addis Abeba,Ethioipia; 2016. 1-23 p.

12. Dagne I, Kebede M, Mekonnen R. PREVALENCE AND ASSOCIATED FACTORS FOR INITIATION. OF INFANT FORMULA FEEDING AMONG MOTHER WHO ATTEND PUBLIC HEALTH INSTITUTE. EUr J Biomed Pharm Sci. 2019;6(2).

13. Abebe L, Aman M, Asfaw S, Gebreyesus H, Teweldemedhin M. Formula-feeding practice and associated factors among urban and rural mothers with infants 0 - 6 months of age: a comparative study in Jimma zone Western. BMC Pediatr. 2019;1-10.

14. Ratna A, Wahyu M. Factors Influencing the Mother in Giving Infant Formula Milk for 0-6 Months Baby. 2018;2:3-8.

15. Pries AM, Huffman SL, Adhikary I, Upreti SR, Dhungel S, Champeny M, et al. Original Article Promotion and prelacteal feeding of breastmilk substitutes among mothers in Kathmandu Valley, Nepal. Matern \$ child Nutr. 2016;12(Mohp 2012):8-21.

16. Legesse M, Demena M, Mesfin F, Haile D. Prelacteal feeding practices and associated factors among mothers of children aged less than 24 months in Raya Kobo district, North Eastern Ethiopia: A crosssectional study. Int Breastfeed J. 2014;9(1):1-8.

17. Akafu W, Geta ET. Magnitude and Determinants of Dropout from Community-Based Health Insurance Among Households in Manna District, Jimma Zone, Southwest Ethiopia. Clin Outcomes Res. 2020; (December).

18. Mekuria G, Edris M. Exclusive breastfeeding and associated factors among mothers in Debre Markos, Northwest Ethiopia: A cross-sectional study. Int Breastfeed J. 2015;10(1):1-7.

19. Central statistical agency (CSA) [Ethiopia] and ICF. Ethiopia demographic and health survey 2016. [Internet]. Ababa, Ethiopia, and Rockville, Maryland, USA: CSA and ICF; 2016 [cited 2021 Feb 23]. Available from: https://dhsprogram.com/pubs/pdf/FR328/FR328.pdf. 
20. Seid SS, Muluneh E, Sinbirro IA, Moga TT, Haso TK, Amme Ibro S. Utilization of Bottle Feeding Practices and Associated Factors among Mothers Who Have Infant Less than 12 Months of Age in Agaro Twon, Jimma Zone South West Ethiopia, 2018. Heal Sci J. 2019;13(1).

21. Kebebe T, Assaye $\mathrm{H}$. Intention, magnitude and factors associated with bottle feeding among mothers of 0-23 months old children in Holeta town, Central Ethiopia: A cross sectional study. BMC Nutr. 2017;3(1):1-7.

22. Asfaw Admasu M. Breastfeeding Knowledge, Attitude, and Practice and Related Determinants Among Maternal in Gondar, Ethiopia: Cross-Sectional Study. Int J Nutr Food Sci. 2016;5(1):25.

23. Tang L, Binns CW, Lee AH. Infant Formula Crisis in China: A Cohort Study in Sichuan Province. 2015;33(1):117-22.

24. Pierro J, Abulaimoun B, Roth P, Blau J. Factors Associated with Supplemental Formula Feeding of Breastfeeding Infants during Postpartum Hospital Stay. Breastfeed Med. 2016;11(4):196-202.

25. Saadia ljaz T, ljaz RK, Asfzal MM, Afzal OM. Infants-feeding practices and their relationship with socio-economic and health conditions in Lahore, Pakistan. Adv life scinece -international querterly $\mathrm{J}$ Biol Sci. 2015.

26. Yee CF, Chin R. Parental perception and attitudes on infant feeding practices and baby milk formula in East Malaysia. Int J Consum Stud ISSN. 2007;31:363-70.

27. Chang PC, Li SF, Yang HY, Wang LC, Weng CY, Chen KF, et al. Factors associated with cessation of exclusive breastfeeding at 1 and 2 months postpartum in Taiwan. Int Breastfeed J. 2019;14(1):1-7.

28. Tan KL. Factors associated with non-exclusive breastfeeding among 4-week post-partum mothers in Klang district, Peninsular Malaysia. Malays J Nutr. 2009;15(1):11-8.

29. Etreby LA, El, Kandeel WA, Rabah TM, Zeid DA, El-din EMS, Metwally AM, et al. Determinants of Exclusive Breastfeeding in a Sample of Egyptian Infants Determinants of Exclusive Breastfeeding in a Sample of Egyptian Infants. 2018;(1772).

30. Elwelely MZ 1. MF 2. Problems Facing Newly Breast Feeding Mothers and the Plan of Nursing Action Nursing Action. IOSR J Nurs Heal Sci. 2018;7:12-9.

31. Khanal V, Scott JA, Lee AH, Karkee R, Binns CW. The supplemental use of infant formula in the context of universal breastfeeding practices in Western Nepal. BMC Pediatr [Internet]. 2016 [cited 2021 Mar 29];16(1):1-7. Available from: http://dx.doi.org/10.1186/s12887-016-0602-1.

32. Nasrul N, Ha F, Ramadhan K, Elizadiani D, Efendi F. Children and Youth Services Review Factors associated with bottle feeding in children aged 0 - 23 months in Indonesia. 2020;116(April):0-4.

33. Khasawneh W, Khasawneh AA. Predictors and barriers to breastfeeding in North of Jordan: Could we do better? Int Breastfeed J. 2017;12(1):1-7.

34. Dimitraki M, Tsikouras P, Manav B, Gioka T, Koutlaki N, Zervoudis S, et al. Evaluation of the effect of natural and emotional stress of labor on lactation and breast-feeding. Arch Gynecol Obstet. 2016;293(2):317-28. 
35. Rynjah MM, Venkatachalam J, Adhisivam B, Olickal JJ, Sundaram SPCP. Non-exclusive breastfeeding amongst high-risk children: Factors and barriers associated with non-exclusive breastfeeding at a tertiary care hospital in Southern India. 2021;(January):19-26.

36. Berde AS. Factors associated with bottle feeding in Namibia: Findings from Namibia 2013 demographic and health survey. J Trop Pediatr. 2017;64(6):460-7.

37. Nuralita AY, Murti B, Pamungkasari EP. Factors Affecting Infant Formula Feeding in Infants Aged 0-6 Months in Sukoharjo, Central Java. J Matern Child Heal. 2017;2:270-83. 